\title{
TOURISM DEVELOPMENT AND SUSTAINABLE WELL-BEING: A BEYOND GDP PERSPECTIVE ${ }^{1}$
}

Larry Dwyer

Business School, University of Technology

Sydney, Australia

\begin{abstract}
:
The Beyond GDP approach to development is gaining widespread support from policy makers and researchers worldwide. While not formulated specifically for tourism activity, the approach serves as a guide to measuring the current and future well-being of destination residents associated with tourism development. Based on ideas and arguments developed in Dwyer (2020), the paper also discusses some key responsibilities of tourism industry stakeholders structured according to several different senses of 'beyond' that characterise the Beyond GDP research agenda. It is argued that research on destination tourism development can learn much from the Beyond GDP approach in respect of conceptual advance, industry practice and policy implementation.
\end{abstract}

Keywords:

Sustainable tourism, Better Life well-being framework, Tourism destination, Beyond GDP, Resident well-being.

\section{INTRODUCTION}

Promoting the well-being of local residents is a fundamental objective of sustainable tourism development. In recent years an increasing volume of tourism-related research has addressed well-being issues as they affect both tourists and destination residents (Uysal, Perdue and Sirgy, 2012; Hartwell, Fyall, Willis, Page, Ladkin, Hemingway, 2018). With some exceptions, studies of resident well-being have tended to focus on current well-being outcomes rather than detailed study of the links between well-being and sustainability.

The overall aim of the paper is to argue the case for measures of sustainable well-being developed within the Beyond GDP research agenda, to play an essential role in formulating, implementing and evaluating tourism development across all destinations.

1 The paper is based on the analysis in the research article previously published in the Journal of Sustainable Tourism: Dwyer, L. (2020). Tourism development and sustainable well-being: a Beyond GDP perspective, Journal of Sustainable Tourism, DOI: $10.1080 / 09669582.2020 .1825457^{\star *}$ 


\section{BEYOND GDP}

GDP relates to the value of the goods and services produced in an economy in a given year. For many decades, gross domestic product (GDP) has been the preferred measure for assessing progress in human development although it was never created for that purpose.

The assumption behind using the GDP to assess wellbeing is that the higher the level of economic production, the better people are able to satisfy their material needs. While this measure is a critical indicator of a country's macro-economic condition and the opportunity afforded to meet material needs, its inadequacy to measure people's lives and well-being has become increasingly acknowledged. Human well-being is a broader concept than economic production and material living standards. It includes the full range of economic, social and environmental factors that influence the overall well-being of people and societies. There is now a solid and well-established case for looking 'beyond GDP', using well-being metrics in the policy process and assessing economic growth in terms of its impact on people's well-being and on societies' standard of living (Fuchs, Schlipphak, Treib, Long and Lederer, 2020).

In the wider social science literature a 'revolution' is taking place that has substantial consequences for the measurement challenges facing tourism development and resident well-being. This revolution, known widely as the Beyond GDP approach, recognising the inadequacy of standard economic measures such as GDP for capturing several critical dimensions of people's well-being, is attempting to develop measures of progress that capture broader aspects of people's living conditions and of the quality of their lives (Bleys, 2012; Radermachier, 2015; Fuchs et al, 2020). To date, a substantial body of research and statistical work providing alternative or complementary metrics of human progress has been developed (Stiglitz, Sen and Fitoussi, 2009a,b; Stigliz, Fitoussi and Durand, 2018). As a consequence, the notion of well-being has received increasing attention in recent years as an agenda for research, measurement and policy. While not developed specifically for tourism, the Beyond GDP approach offers comprehensive and realistic ways to measure destination sustainability and well-being, as well as policy recommendations that can guide tourism development to best sustain resident well-being over the long-run.

The preferred option of the Beyond GDP agenda is to develop a dashboard of well-being measures to complement GDP and other economic indicators, rather than discard or modify the concept itself. The statistical agenda of the Beyond GDP approach is progressively moving towards the development of internationally comparable measures of well-being to better understand people's lives at the individual, household and community level. As study of well-being matures as a statistical and measurement agenda, it has become increasingly relevant as a 'compass' to guide policy, generating more meaningful metrics of well-being and progress and embedding these metrics in public policy assessment Maintaining the Integrity of the Specifications.

The template is used to format your paper and style the text. All margins, column widths, line spaces, and text fonts are prescribed; please do not alter them. You may note peculiarities. For example, the head margin in this template measures proportionately more than is customary. This measurement and others are deliberate, using specifications that anticipate your paper as one part of the entire proceedings, and not as an independent document. Please do not revise any of the current designations.

\section{DIMENSIONS OF WELL-BEING}

Given the complexity of the well-being concept, a single indicator will not be sufficient. A comprehensive set of integrated indicators is likely to be most effective at providing measures for policy purposes. The social science literature offers diverse perspectives as to the nature of 'well-being', its drivers and its indicators (Musikanski, 2015). 'Well-being' is widely agreed to be a multi-dimensional concept that incorporates notions of material comforts, individual freedoms, opportunities, mental states and capabilities (Durand, 2015; Helliwell, Layard and Sachs, 2019).

Given the need for well-being estimates to inform tourism development paths, the measures used by tourism researchers must be credible with a sound basis in theory. The most highly regarded conceptual framework for understanding and measuring well-being and societal progress, emerging from the Beyond GDP agenda is, arguably, the Better Life framework (OECD, 2011; Durand, 2015). 
This framework identifies three pillars for understanding and measuring resident current and future wellbeing: material living conditions; quality of life; and sustainability.

Material living conditions comprise income and wealth, jobs and earnings and housing.

Quality of Life is captured through an additional eight dimensions that shape people's lives. These are health, work-life balance, education and training, social connections, civic engagement and governance, environmental quality, personal security, and subjective well-being.

Sustainability is measured using indicators associated with four different types of 'capital'- economic, human social and natural. The level of each type of capital stock is essential for sustaining well-being outcomes over time.

The Better Life framework incorporates many of the well-being dimensions emphasised in other approaches. The framework's distinguishing features are its recognition of the importance of both subjective and objective dimensions of well-being and its distinction between the drivers of current and future well-being, thus embedding sustainability considerations into the framework. The framework is flexible enough to include additional dimensions and indicators of well-being into the overall framework of analysis as these are developed by researchers, industry practitioners and policy makers. A dashboard of interlinked indicators developed with the approach has evolved into the Better Life Index, an interactive web platform that allows individuals and communities to set their own weights on each of the different dimensions of the wellbeing framework. The Better Life Index encourages residents to participate in the debate on destination progress, and to identify what matters most in their lives. Although a number of measures of wellbeing are still under development, the quality of data and the empirical robustness of measures may be expected to progress over time (Stiglitz et al, 2018).

\section{IMPLICATIONS FOR TOURISM RESEARCH AND PRACTICE}

Several themes arising from the Beyond GDP approach may be expected to drive sustainability theory development and policy making into the future. If tourism stakeholders are to give serious attention to the implications of the Beyond GDP approach and its application of a 'well-being lens' to guide and assess destination development, a number of challenges must be met. Confronting these challenges implies that stakeholders must address several different notions of 'beyond'.

Beyond Perceptions. Tourism research has tended to focus on subjective measures of tourist and resident well-being, collecting relatively easily collected survey data on 'perceptions' and 'satisfactions'. However, this neglects the influence of objective determinants of resident well-being. More robust measures of current and future well-being beyond resident perceptions are necessary if resident attitudes or perceptions are to link with the different drivers of well-being. Indeed future well-being, dependent as it is on changing levels and qualities of capital stocks, cannot be addressed in detail in the absence of objective (physical or monetary) measures to complement subjective measures.

Beyond Competitiveness. Tourism researchers agree that the ultimate rationale for achieving a competitive tourism industry is to enhance the well-being of its resident stakeholders. Destination competitiveness studies and frameworks have tended to incorporate well-being into their analyses in an ad hoc rather than strategic manner. However, the link between destination competitiveness and resident well-being remains relatively neglected. Detailed research needs to be undertaken both at a conceptual and empirical level to integrate wellbeing goals into destination competitiveness studies

Beyond the 'here and 'now'. The Beyond GDP agenda implies that sustainability study must distinguish and balance two forms of distributional justice - inter-generational and the intra-generational. Tourism research needs to pay more attention to the effects of tourism- induced effects on future as well as current well-being. To properly assess tourism's role in path development researchers must focus on the links to well-being of changes in each of the four capitals.

- If the real per capita value of the capital stocks is increasing over time, destination development may be sustainable resulting in increased resident well-being.

- If real per capita value of the capital stocks is falling over time destination development is unsustainable resulting in decreased well-being in the future. 
There is an urgent need also to understand the interactions, substitutability, complementarity and trade-offs between them. The Better Life framework can provide the basis of a practical set of tools for policy analysts to more clearly incorporate the four capitals into well-being assessment generally and for tourism specifically.

Beyond the market. Assessing the sustainability of a given tourism development path ideally requires monetary estimates of changes in the capital stocks that contribute to people's well-being. On the capitals approach, measuring sustainability requires focus on the net change in the volumes of the stocks of various assets, weighted by their 'shadow prices', a monetary value reflecting the true opportunity costs of all activities, taking into account all generated externalities and public goods. A well-established range of methods exist to estimate the value of capital stocks in the absence of market prices (Stiglitz et al, 2009a,b; Stiglitz, 2018).. Ongoing research is developing better measures of human capital, social capital and natural capital. Various techniques can be used in shadow pricing. These techniques are familiar to tourism economists and have been employed in a variety of evaluation contexts. Estimating the effects of changing capital stocks on well-being is an additional challenge that researchers are now addressing in greater detail.

Beyond Weak Sustainability. Achieving sustainable tourism development involves making important decisions about what types of capital can be used up in the present and what must be preserved for the future. The weak sustainability view implies that the four types of capitals are interchangeable in terms of maintaining well-being over time. In contrast, strong sustainability asserts that some types of capital (particularly natural capital) are to a greater and lesser extent non-substitutable in the production process. While a large proportion of tourism researchers appear implicitly to adopt a strong sustainability view, the theoretical and practical implications of applying strong sustainability conditions in tourism planning and development have been unduly neglected. Tourism researchers need to better appreciate the essential dynamic dimension of sustainable development, unable to be captured within static models.

Beyond CSR. The Beyond GDP agenda on responsible business conduct calls for a new mindset that moves away from the standard Corporate Social Responsibility (CSR) injunction to 'do no harm' towards an approach of 'doing good' (Bleys, 2012). This implies that social and environmental impacts of firm operations and well-being outcomes should be built into firms' mission statements and business models, rather than being addressed as 'optional extras'. Opportunities exist for tourism researchers to extend to businesses the well-being lens that is core to the Beyond GDP approach while exploring the advantages of different types of business models that firms can adopt consistent with this approach.

Beyond silos. Policymaking often operates in silos, with decision makers in different government departments and different industries focusing on the resources and outputs for which they are directly accountable and without reference to the wider impacts of their actions in areas not directly under their responsibility. Adopting the wellbeing framework, promoting more comprehensive evaluations of the impact of specific policies on people's lives, can allow DMO and other tourism stakeholders to play a more substantive role in the wider process of economic development. Ultimately, breaking down the silos in fulfilment of the Beyond GDP agenda, requires building well-being into the machinery of government, and the tools used to take decisions.

Beyond Borders. Going beyond the silos in respect of well-being study also implies a greater effort to measure the international aspects of sustainable development, beyond destination borders. In an increasingly globalised world, a destination attempting to enhance the well-being of its citizens will also affect the well-being of citizens of other countries. A classic example is that of a destination's carbon emissions, adding to global warming. The sustainability challenge is thus of global importance as well as destination importance since unsustainable development can have transboundary effects on human well-being. DMO, through the UNWTO, can play an important advocacy role in encouraging national statistical agencies and international organisations to harmonise their well-being indicator sets, so that they are better suited for international comparison.

Beyond the Barriers. If measures of resident well-being are to make a real difference to people's lives, they must be explicitly employed in the tourism policy-making process. Important barriers to employing well-being frameworks in policy settings include lack of political imperative or government support for development of well-being measures 'Beyond GDP' and institutional resistance to change. The neoliberal belief that GDP growth is the prime goal of development is perhaps the biggest barrier to the development of better measures of destination progress. Efforts to develop statistical capacity in tourism and/or well-being may also compete with other statistical priorities. The development of new well-being measures that are more tourism-focussed will be challenging in destinations with limited statistical resources. 


\section{CONCLUSIONS}

The Better Life framework, developed within the Beyond GDP approach, provides a sound and relevant theoretical foundation for well-being study, with policy relevant economic, quality of life and sustainability indicators. While the Better Life well-being framework does not specifically address tourism, the suggested measures are capable of informing tourism stakeholders as to the essential role that well-being considerations might play in industry and wider economic development both currently and in the future. Many of the identified indicators will change over time as better measures are developed, and as destination policy makers reach agreement on indicators that better capture conditions in the various dimensions of residents' lives. DMO, industry and tourism researchers can play an important role in indicator development in general and particularly as regards the relevance of various existing and 'experimental statistics' for tourism contexts. The opportunity now exists for tourism researchers giving serious attention to the application of a 'well-being lens' to guide destination development to explore both the theoretical challenges associated with well-being and indicator development and the practical implications of the Better Life framework for policy making linked with destination management.

\section{REFERENCES}

Bleys, B. (2012) 'Beyond GDP: Classifying alternative measures for progress' Social Indicators Research, 109(3), pp.355-376. DOI: 10.1007/s11205-011-9906-6

Dwyer L. (2020) Tourism Development and Sustainable Well-being: a Beyond GDP Perspective forthcoming, Journal of Sustainable Tourism. DOI: 10.1080/09669582.2020.1825457

Durand, M. (2015) 'The OECD better life initiative: How's life? and the measurement of well-being'. Review of Income and Wealth, 61(1), pp.4-17. DOI: 10.1111/roiw.12156

Fuchs, D., Schlipphak, B., Treib, O., Long, L.A.N. and Lederer, M. (2020) 'Which Way Forward in Measuring the Quality of Life? A Critical Analysis of Sustainability and Well-Being Indicator Sets', Global Environmental Politics, 20(2), pp.12-36. DOI: 10.1162/glep_a_00554

Hartwell H, Fyall A, Willis C, Page S, Ladkin A, Hemingway A. (2018) 'Progress in tourism and destination wellbeing research'. Current Issues in Tourism. 2; 21(16):1830-1892. DOI: 10.1080/13683500.2016.1223609

Helliwell, J.F., R. Layard and J.D. Sachs (eds.) (2019), World Happiness Report 2018, Sustainable Development Solutions Network, New York, Retrieved from http://worldhappiness.report/ed/2018/.

Musikanski, L. (2015) 'Measuring happiness to guide public policy making: A survey of instruments and policy initiatives'. Journal of Social Change, 7(1), p.39-55. DOI: 10.5590/JOSC.2015.07.1.04

OECD (2011), How's Life?: Measuring well-being, OECD Publishing. Paris, Retrieved from http://www.oecd. $\mathrm{org} /$ statistics/measuring-well-being-and-progress.htm>

Radermachier, W J (2015). Recent and future developments related to 'GDP and Beyond'. Review of Income and Wealth. 61(1). 18-24. DOI: 10.1111/roiw.12135

Stiglitz, J., Sen, A. and Fitoussi, J.P. (2009a) The measurement of economic performance and social progress revisited. Reflections and overview. Commission on the Measurement of Economic Performance and Social Progress, Paris. Retrieved from http://www.stiglitz-sen-fitoussi.fr/documents/rapport_anglais.pdf

Stiglitz, J.E., A. Sen and J.-P. Fitoussi (2009b), Mismeasuring Our Lives: Why GDP Doesn’t Add Up, The New Press, New York.

Stiglitz, J., J. Fitoussi and M. Durand (2018), Beyond GDP: Measuring What Counts for Economic and Social Performance, OECD Publishing, Paris. DOI:10.1787/9789264307292-en

Uysal, M., Perdue, R. and Sirgy, M.J. eds. (2012) Handbook of tourism and quality-of-life research: Enhancing the lives of tourists and residents of host communities. Springer Science \& Business Media, New York. DOI: $10.1007 / 978-94-007-2288-0$ 